\title{
Clinical Significance of Decompressive Craniectomy Surface Area and Side
}

\author{
KwangWook Jo, ${ }^{1}$ Won Il Joo, ${ }^{2}$ Do Sung Yoo, ${ }^{2}$ Hae-Kwan Park ${ }^{2}$ \\ Department of Neurosurgery,' Bucheon St. Mary's Hospital, College of Medicine, The Catholic University of Korea, Seoul, Korea \\ Department of Neurosurgery, ${ }^{2}$ Eunpyeong St. Mary's Hospital, College of Medicine, The Catholic University of Korea, Seoul, Korea
}

Objective : Decompressive craniectomy (DC) can partially remove the unyielding skull vault and make affordable space for the expansion of swelling brain contents. The objective of this study was to compare clinical outcome according to DC surface area (DC area) and side.

Methods : A total of 324 patients underwent different surgical methods (unilateral DC, 212 cases and bilateral DC, 112 cases) were included in this retrospective analysis. Their mean age was $53.4 \pm 16.6$ years (median, 54 years). Neurological outcome (Glasgow outcome scale), ventricular intracranial pressure (ICP), and midline shift change (preoperative minus postoperative) were compared according to surgical methods and total DC area, DC surface removal rate (DC\%) and side.

Results : DC surgery was effective for ICP decrease $(32.3 \pm 16.7 \mathrm{mmHg}$ vs. $19.2 \pm 13.4 \mathrm{mmHg}, p<0.001)$ and midline shift change $(12.5 \pm 7.6$ $\mathrm{mm}$ vs. $7.8 \pm 6.9 \mathrm{~mm}, p<0.001)$. The bilateral $D C$ group showed larger total $D C$ area $\left(125.1 \pm 27.8 \mathrm{~cm}^{2}\right.$ for unilateral vs. $198.2 \pm 43.0 \mathrm{~cm}^{2}$ for bilateral, $p<0.001$ ). Clinical outcomes were nonsignificant according to surgical side (favorable outcome, $p=0.173$ and mortality, $p=0.470$ ), significantly better when total DC area was over $160 \mathrm{~cm}^{2}$ and DC\% was $46 \%$ ( $p=0.020$ and $p=0.037$, respectively).

Conclusion : DC surgery is effective in decrease the elevated ICP, decrease the midline shift and improve the clinical outcome in massive brain swelling patient. Total DC area and removal rate was larger in bilateral DC than unilateral DC but clinical outcome was not influenced by DC side. DC area more than $160 \mathrm{~cm}^{2}$ and DC surface removal rate more than $46 \%$ were more important than DC side.

Key Words : Skull · Decompressive craniectomy · Intracranial pressure · Prognosis · Craniectomy size.

\section{INTRODUCTION}

Since the brain is encased in the unyielding skull vault, any increase in its volume will increase the intracranial pressure (ICP) and result in critical outcomes. Decompressive craniectomy (DC) can partially remove the unyielding skull vault and make an affordable space for the expansion of swelling brain contents. The limited brain space is increased after the DC. This might decrease ICP, thus improving the cerebral perfusion pressure $(\mathrm{CPP})^{2-4,19,25,26,30,33,39,41)}$. Increased ICP is a major predictor of poor prognosis or death of patients with traumatic brain injury (TBI) $)^{5,611,19,25,28,30,33,34,36,37)}$. Despite the highly de-

- Received : May 22, 2020 •Revised : June 25, 2020 •Accepted : July 2, 2020

- Address for reprints : Do Sung Yoo

Department of Neurosurgery, Eunpyeong St. Mary's Hospital, College of Medicine, The Catholic University of Korea, 1021 Tongil-ro, Eunpyeong-gu, Seoul 03312, Korea Tel : +82-2-2030-4491, Fax : +82-32-340-7391, E-mail : yooman@catholic.ac.kr, ORCID : https://orcid.org/0000-0003-2569-6502

This is an Open Access article distributed under the terms of the Creative Commons Attribution Non-Commercial License (http://creativecommons.org/licenses/by-nc/4.0) which permits unrestricted non-commercial use, distribution, and reproduction in any medium, provided the original work is properly cited. 
veloped medical treatment options, DC might be the last and very effective treatment option for patients with intractable increase of $\mathrm{ICP}^{1,8-11,13,33)}$.

Many previous studies have reported benefits and limitations of DC in $\mathrm{TBI}^{2,3,6,10,11,15,20,30,33,37)}$, hypertensive intracerebral hemorrhage $(\mathrm{HICH})^{4,12,15,40)}$, major infarction $(\mathrm{MI})^{13,15,17,21,23,32,35,42)}$, and aneurysmal subarachnoid hemorrhage $(\mathrm{SAH})^{15,35)}$. These reports were concerned with the DC. They were performed using various DC surgical methods, such as bifrontal craniectomy, unilateral or bilateral hemi-craniectomy, suboccipital craniectomy, and non-specific craniectomy with various sizes. Several reports have compared DC effects according to causative diseases, with various results according to the study ${ }^{15,37)}$. Accumulating data have proven that DC is effective in ICP treatment for improving cerebral perfusion and neurologic outcomes $2,3,6,10,12,13,18,25,26,30,33,37)$.
Recent papers recommend larger DC area is essential for improve the neurologic outcomes ${ }^{8)}$. However, it is very rare that has compared DC effects according to surgical methods. These authors usually prefer DC for the last step in treating massive brain swelling patients. Sometimes surgical method, unilateral or bilateral DC, is also a variable and also DC area is a variable. In this study, clinical effects were compared with Glasgow outcome scale (GOS; at 6 months after DC), ICP control effect (initial ICP-postoperative mean ICP), and midline shift improvement (midline shift preoperative-24 hours after operation) according to decompressive bone size. Decompressive bone size (total DC area and major side DC area) was also compared between unilateral and bilateral DC.

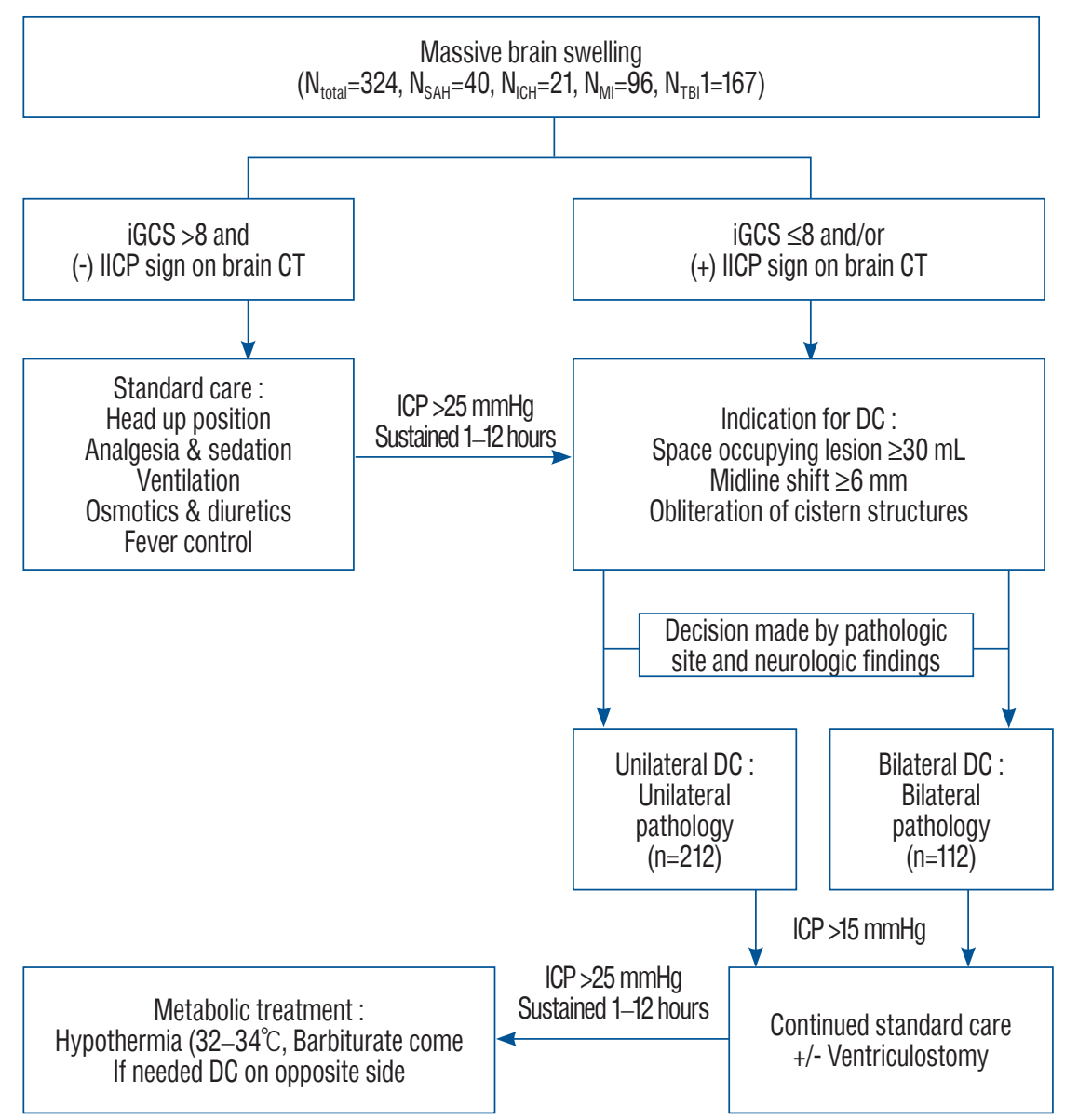

Fig. 1. Flow sheet of treatment protocol. SAH : subarachnoid hemorrhage, ICH : intracerebral hemorrhage, $\mathrm{MI}:$ major infarction, TBI : traumatic brain injury, iGCS : initial Glasgow coma scale, iICP : intracranial pressure after ventricular puncture, CT : computed tomography, DC : decompressive craniectomy. 


\section{MATERIALS AND METHODS}

The treatment protocol (Fig. 1) was approved by the Institutional Review Board of Eunpyeong St. Mary's Hospital (PC17RES10027). All patients or their representatives provided informed written consent for surgical management. This study was a retrospective study through observatory data analysis.

\section{Patient population}

Between September 2012 and August 2019, patients underwent DC. They were monitored for ICP during and after the surgery. In these patients, initial ICP, postoperative ICP, mean arterial blood pressure, CPP, and decompression bone size were measured. A total of 324 patients who underwent unilateral DC (212 patients) or bilateral DC (112 patients) were included in this retrospective analysis, consisting of aneurysmal SAH (40 cases), massive intracranial hemorrhage (ICH; 21 cases), MI (96 cases), and TBI (167 cases). Seventeen patients
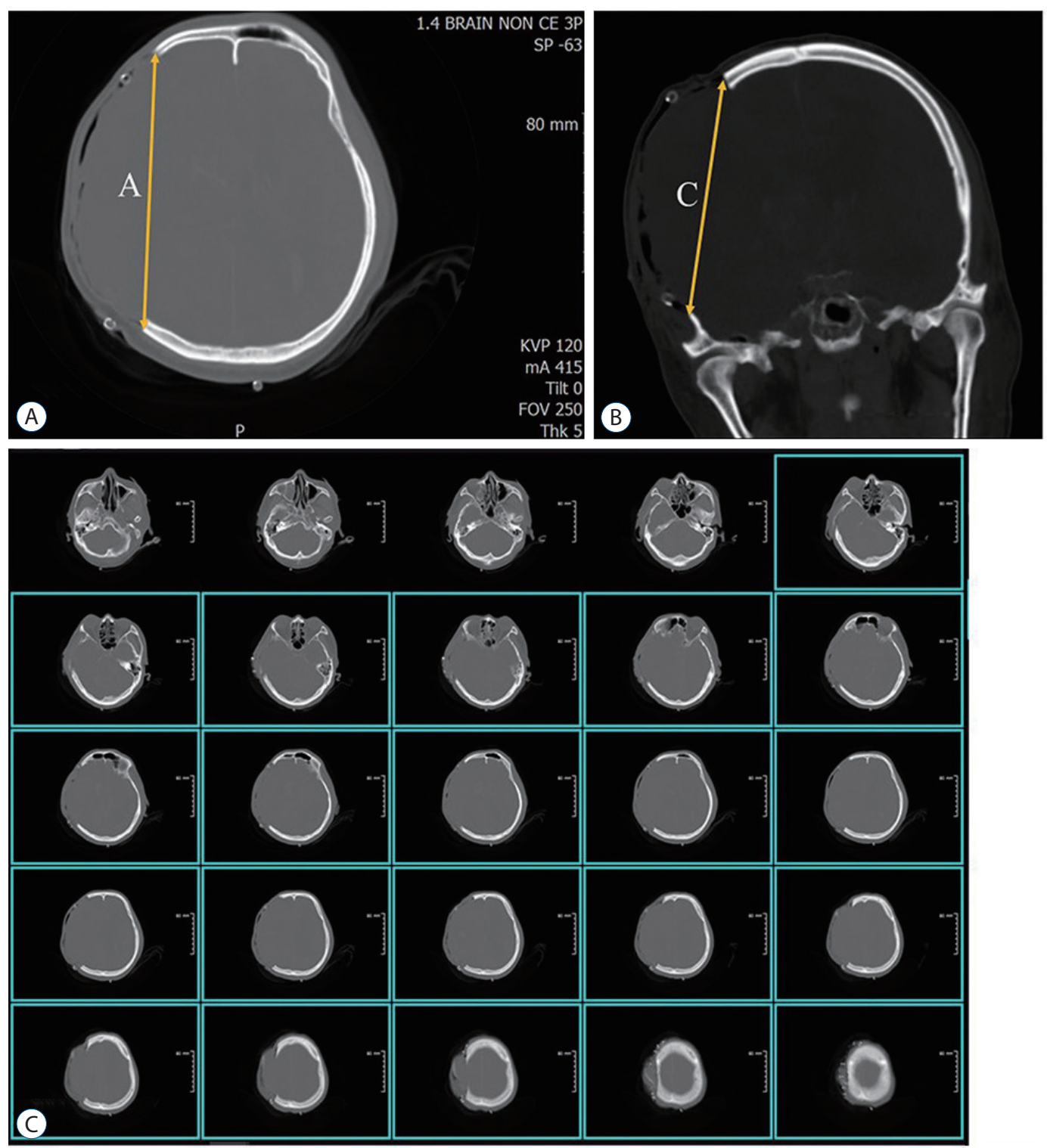

Fig. 2. The simple $A C$ methods for calculating $D C$ area. $A: A$ was the longest length of craniectomy on the axial slices. $B: C$ was the longest length of craniectomy on the coronal slice. C : C could be calculated the number of axial cuts (the number of blue box) by craniectomy and slice thickness (red box, $5 \mathrm{~mm})$. DC : decompressive craniectomy. 
underwent multiple DC operation (one patient three times). They were not included in this study. The mean age of all patients was 53.4 years (median, 54 years; male : female, 225 : 99). Standard image study, included computed tomography (CT) scanning undertook as soon as the patient arrival in the emergency room or showing neurological deterioration (decrease Glasgow coma scale [GCS] more than 2 grade or National Institute of Health Stroke Scale more than score 4). All these preoperative brain CT were performed within three hours prior to DC surgery.

\section{Indications for surgery}

Indications for decompressive surgery included appearance of definite brain swelling on CT scan as indicated by a midline shift of more than $6 \mathrm{~mm}$ and/or obliteration of the cistern structures and space occupying lesion more than $30 \mathrm{~mL}$. Clinical deterioration was defined as worsening neurological status (GCS score of less than 8 or rapid decreasing GCS score of more than 2 points). Patients who showed brainstem failure without spontaneous respirations did not undergo DC surgery $^{23,24,27)}$. Surgical methods (unilateral or bilateral hemicraniectomy) and DC area were decided by pathologic site and neurologic findings (Fig. 2).

\section{Operation procedures}

The operation was carried out under general endotracheal anesthesia for all patients. Patient was placed in a supine position. For patients undergoing bilateral hemi-craniectomy, the head was positioned straight and somewhat extended on the head-rest so that the occipital area is in most dependent position. For patients undergoing unilateral hemi-craniectomy, the head was turned to the opposite side as far as the operation side. The ventricular puncture was performed at Kocher's point on the opposite side of the offending lesion or right side for the cases with no definite offending lesion. For some cases, a navigation system was used for accurate ventricular puncture. An extraventricular drainage (EVD) tube (EVD catheter; Yushin Medical, Seoul, Korea) was connected to the continuous monitor (CPP-monitor; Spiegelberg, Hamburg, Germany) via transducer device (Druckmeß-set; Smiths industries, Bayern, Germany). Large bicoronal skin flap was made for bilateral DC patients while large question mark flap was made for unilateral DC patients. Their limbs were placed behind the parietal eminence, extending inferiorly to the zygoma on both or operation sides. The scalp was then dissected sub-periostealy to the level of supraorbital ridges. After the ventricular ICP was stabilized, 2 or 3 burr holes were connected with a pneumatic saw, with subsequent removal of bone flap. In bilateral DC patients, the frontal median segment of the bone measuring about $3-4 \mathrm{~cm}$ in width along the sagittal sinus was saved in order not to damage the sagittal sinus and to function as a framework for later cranioplasty. Additional bone was removed at the temporal region to the floor of the middle fossa (Fig. 1). The dura was then opened in a large cruciated or curved $\mathrm{Z}$ shaped incision in areas involving frontal, temporal, and parietal lobes. When the dura was opened, underlying brain or hematoma typically herniated outward. Cortical resection of the brain was not performed. In all DC patients, artificial dura (Lyoplant; B. Braun Melsungen AG, Melsungen, Germany) was placed underneath the incised dura to allow the brain to herniate outward in a more controlled manner and to prevent cortical adhesion. After that, several pieces of gel-forms were inserted between the dura and muscle layer to control postoperative bleeding and allow easy dissection for cranioplasty afterward. Temporalis muscle and skin flap were then reapproximated with sutures. The bone flap was typically maintained in wet gauze at $-70^{\circ} \mathrm{C}$ until reinsertion at $6-12$ weeks after the initial surgery.

\section{Postoperative management}

If the ventricular pressure exceeded $15 \mathrm{mmHg}$ after decompressive surgery, conventional medical management methods including the use of hyperosmotic agents and EVD were initiated. If the ventricular pressure exceeded $25 \mathrm{mmHg}$, regardless of medical therapy, either hypothermia (rectal temperature, $32-34^{\circ} \mathrm{C}$ ) or coma therapy was initiated with a cold blanket and/or barbiturate.

\section{Determination of decompression bone size}

DC area was determined by directly multiplying long and short diameters of bone fragments in the operating room with an autoclaved ruler. If sizing of the bone fragment was missed in the operating room, 3D CT reconstruction image was undertaken to measure long and short diameters of the skull bone defect area. DC area was calculated using the simple AC method $^{16)}$. A was the longest length of craniectomy on the axial slices (Fig. 2A), and $\mathrm{C}$ was the longest length of craniectomy on the coronal slice (Fig. 2B). If the coronal slice did not exist, 
C was calculated the number of axial cuts by craniectomy and slice thickness (Fig. 2C). Total DC area of bilateral DC was calculated sum of each DC area. In this study, total cranial vault surface area was estimated as half of the sphere surface area. The radius was defined as the mean of the half distance from glabella to inion plus half distance from external auditory canal to vertex. Total DC area was defined as the sum of both sides of DC area if it was a bilateral DC case. DC area percent was calculated as DC area divided by the total cranial vault surface area. Offending side DC surface removal rate (DC\%) was defined as DC area divided by half of the cranial vault surface area in the pathologic side.

\section{Data collection}

Neurologic outcome was evaluated at 6 months after the initial surgery. Favorable outcome (GOS 4-5) and mortality rate were compared according to surgical methods (unilateral vs. bilateral DC) and DC area. The initial ICP reading was considered to be the highest sustained ventricular pressure for 5-10 minutes after ventricular puncture. Ventricular pressure values were collected using continuous monitoring during intraoperative and postoperative periods (data were analyzed between postoperative $2-5$ days). The midline shift was defined as the distance from the septum pellucidum to the midline between the anterior (crista galli) and posterior (torcular herophili).

Table 1. Demographic and clinical features of 324 patients according to DC method

\begin{tabular}{|c|c|c|c|c|}
\hline Characteristic & Total $(n=324)$ & Unilateral $(n=212)$ & Bilateral $(n=112)$ & $p$-value \\
\hline Age (years) & $53.4 \pm 16.6(54)$ & $56.2 \pm 16.2(56)$ & $48.1 \pm 16.0(48)$ & 0.989 \\
\hline Male & $225(69.4)$ & $152(71.7)$ & $73(65.2)$ & 0.139 \\
\hline iGCS & $6.5 \pm 2.3(7.0)$ & $6.6 \pm 2.5(7.0)$ & $6.3 \pm 1.8(6.0)$ & 0.001 \\
\hline To OP time (hours) & $19.0 \pm 29.2(6.0)$ & $14.4 \pm 31.5(5)$ & $21.9 \pm 23.6(10.5)$ & 0.241 \\
\hline Midline shift (mm) & $12.5 \pm 7.6(12.0)$ & $12.8 \pm 5.9(12)$ & $11.9 \pm 10.0(12.0)$ & 0.361 \\
\hline Midline shift, 24 hours after OP (mm) & $7.8 \pm 6.9(5)$ & $8.3 \pm 6.2(7)$ & $6.9 \pm 8.1(4)$ & 0.687 \\
\hline ilCP $(\mathrm{mmHg})$ & $32.3 \pm 16.7(30.0)$ & $30.5 \pm 16.3(20.0)$ & $35.6 \pm 16.9(30.2)$ & 0.807 \\
\hline vICP, mean value after $\mathrm{OP}(\mathrm{mmHg})$ & $19.2 \pm 13.4(14.7)$ & $20.0 \pm 13.3(14.5)$ & $19.7 \pm 13.7(14.9)$ & 0.994 \\
\hline Total DC area $\left(\mathrm{cm}^{2}\right)$ & $150.5 \pm 48.5(144.0)$ & $125.1 \pm 27.8(124.0)$ & $198.2 \pm 43.0(189.8)$ & $<0.001$ \\
\hline Total DC\% & $42.4 \pm 13.3(39.1)$ & $34.5 \pm 6.5(35.3)$ & $57.3 \pm 9.7(57.0)$ & $<0.001$ \\
\hline Offend side DC area $\left(\mathrm{cm}^{2}\right)$ & $121.1 \pm 27.7$ (119.6) & $125.1 \pm 27.8(126.0)$ & $113.6 \pm 25.9(108.0)$ & 0.753 \\
\hline Offend side DC\% & $67.9 \pm 12.9(69.3)$ & $69.1 \pm 13.0(70.5)$ & $65.7 \pm 12.2(64.5)$ & 0.669 \\
\hline ICP-difference & $13.1 \pm 13.2(13.6)$ & $11.6 \pm 13.2(12.0)$ & $15.9 \pm 12.8(16.0)$ & 0.441 \\
\hline Midline shift difference & $4.6 \pm 7.4(5.0)$ & $4.4 \pm 5.3(5.0)$ & $5.0 \pm 10.3(6.0)$ & 0.015 \\
\hline \multicolumn{5}{|l|}{ Clinical outcomes, GOS } \\
\hline 1, death & $121(37.3)$ & $80(37.7)$ & 41 (36.6) & 0.173 \\
\hline 2 & $68(21.0)$ & 38 (17.9) & $30(26.8)$ & \\
\hline 3 & $45(13.9)$ & $31(14.6)$ & $14(12.5)$ & \\
\hline $4+5$, favor & $90(27.8)$ & $63(29.7)$ & $27(24.1)$ & 0.470 \\
\hline 4 & $34(10.5)$ & $19(9.0)$ & $15(13.4)$ & \\
\hline 5 & $56(17.3)$ & $44(20.8)$ & $12(10.7)$ & \\
\hline
\end{tabular}

Values are expressed as mean \pm standard deviation (median), mean \pm standard deviation (\%), or number (\%). DC : decompression craniectomy, iGCS : initial Glasgow coma scale, To OP times : accident to operation time, Midline shift : midline shift on brain computed tomography before the decompression craniectomy, ilCP : intracranial pressure after ventricular puncture, vICP : ventricular intracranial pressure after DC operation, Total DC area and DC\% : craniectomized bone sized and percentage of craniectomized bone sized over the total cranial vault size, Offend side DC area and DC\% : craniectomized bone sized and percentage of craniectomized bone sized over the main pathologic side cranial vault size, GOS : Glasgow outcome scale 


\section{Statistical analysis}

All data are presented as means \pm standard deviations and/or medians. A Wilcoxon signed-rank sum test was used to analyze GCS and GOS scores. Comparisons among groups were performed using unpaired t-test and Fisher's exact test. Statistical analyses for each outcome were analyzed with SPSS software version 12 (SPSS Inc., Chicago, IL, USA). For all statistical analyses, significance was defined at $p \leq 0.05$.

\section{RESULTS}

\section{Comparison of ICP before and after the DC sur- gery}

DC surgery was effective for ICP change $(32.3 \pm 16.7 \mathrm{mmHg}$ vs. $19.2 \pm 13.4 \mathrm{mmHg}, p<0.001)$ and midline shift change (12.5 $\pm 7.6 \mathrm{~mm}$ vs. $7.8 \pm 6.9 \mathrm{~mm}, p<0.001)$ before and after DC surgery (Table 1).

\section{Comparison of clinical results between unilateral and bilateral DC}

Total DC area was larger in the bilateral DC group (198.2 \pm $43.0 \mathrm{~cm}^{2}$ vs. $\left.125.1 \pm 27.8 \mathrm{~cm}^{2}, p<0.001\right)$. And the offending side DC area was larger in the unilateral group, although the difference was not statistically significant $\left(113.6 \pm 25.9 \mathrm{~cm}^{2}\right.$ vs. $125.1 \pm 27.8 \mathrm{~cm}^{2}, p=0.753$ ) (Table 1 ).

The initial GCS $(p=0.001)$ and neurologic outcome (GOS, $p=0.009)$ was better in the unilateral group. The initial ICP ( $p=0.807)$, postoperative ICP $(p=0.994)$, and ICP change (initial ICP-postoperative ventricular ICP, $p=0.441$ ) were similar between unilateral and bilateral DC groups. Midline shift change (preoperative-postoperative midline shift) was only statistically significant in the bilateral DC group $(p=0.015)$ (Table 1).

\section{Correlations between clinical outcomes and DC area}

Total DC area and total DC\% failed to show significant correlations with neurologic outcome (GOS : $p=0.170$ and $p=0.396$, respectively). Total DC area was not correlated with ICP change ( $p=0.147)$. However, large total DC\% was correlated well with ICP change ( $p=0.021)$. Total DC area and total DC\% were correlated with midline shift improvement $(p=0.003$ and $p=0.002$, respectively).
Offending side DC area and offending side DC\% failed to show significant correlations with neurologic outcome (GOS : $p=0.805$ and $p=0.567$ ). Offending side DC area and DC\% failed to show significant correlation with ICP change either ( $p=0.195$ and $p=0.871$ ), although they showed significant correlations with midline shift change.

Total DC area over $160 \mathrm{~cm}^{2}$ and DC\% over 46\% showed statistically better neurologic outcome ( $p=0.020$ and $p=0.037$ ).

\section{DISCUSSION}

DC has been performed for uncontrollable brain swelling since the early 20th century. Kocher (1901) and Cushing (1905) might be the first ones who described surgical decompressive craniectomies for therapeutic purpose in neurosurgical histo$\mathrm{ry}^{22,25)}$. DC is very effective in reducing the elevated ICP caused by brain swelling. It is well associated with improved neurologic outcomes $2,3,11,13,23,30,33,37,39,41)$. Many papers have reported that DC can be a lifesaving procedure in various neurosurgical disorders, including $\mathrm{TBI}^{2,3,10,11,15,20,30,33,37)}, \mathrm{ICH}^{4,12,15,39)}$, $\mathrm{MI}^{13,15,17,21,23,32,38,42)}, \mathrm{SAH}^{15,35)}$, and other brain pathologies ${ }^{15,18,26)}$.

Since the brain is encased in the unyielding skull vault, any increase in its volume makes the ICP to be above the physiological level. The therapeutic principle of DC is to remove a part of cranial vault and give brain tissue room to expand. Therefore, it increases the compliance which results in a rightshift of the pressure-volume curve. At last, DC can lower the ICP and improve CPP, cerebral blood flow, and brain tissue oxygenation $^{2-6,19,25,26,30,37,41)}$.

Several surgical methods of DC have been defined depending on the location and size of bone removal ${ }^{10,12,13,20,23,25,33)}$. Reviewing previous reports, bifrontal craniectomy, unilateral or bilateral hemicraniectomy, and suboccipital craniectomy might be the most common adopted surgical methods for cranial decompression $^{10,12,13,15,17,21,24,25,30,37,41)}$. Many studies have reported benefits and limitations of DC and compared surgical effects according to causative diseases ${ }^{15,24,39)}$. Some reports insist that DC should be as large as possible or bone fragment to be removed should be at least $12 \times 15 \mathrm{~cm}$ in size or have a diameter of $15 \mathrm{~cm}^{8,29,31)}$.

In our data included, those who underwent unilateral or bilateral hemicraniectomy for supra-tentorial pathologies included four disease entities : anterior circulation cerebral an- 
Decompressive Craniectomy Surface Area | Jo KW, et al.

Table 2. Demographic and clinical features of patients according to etiology

\begin{tabular}{|c|c|c|c|c|}
\hline Characteristic & Aneurysm $(n=40)$ & $\mathrm{ICH}(\mathrm{n}=21)$ & Major infarction $(n=96)$ & TBI $(n=167)$ \\
\hline Age (years) & $53.0 \pm 12.2(51)$ & $51.2 \pm 12.5(49)$ & $55.6 \pm 14.8(56)$ & $52.5 \pm 18.7(54)$ \\
\hline Male & $20(50.0)$ & $16(76.2)$ & $57(59.4)$ & $132(79.0)$ \\
\hline iGCS & $5.7 \pm 1.4(6)$ & $5.9 \pm 1.9(6)$ & $7.1 \pm 1.4(8)$ & $6.4 \pm 2.7(6)$ \\
\hline To OP time (hours) & $8.8 \pm 10.5(6.0)$ & $7.8 \pm 10.6(5)$ & $40.9 \pm 44.3(32.0)$ & $6.4 \pm 4.9(4.5)$ \\
\hline Midline shift (mm) & $9.5 \pm 14.4(9.0)$ & $14.6 \pm 5.5(14.5)$ & $14.1 \pm 4.9(14.0)$ & $12.0 \pm 6.4(12.0)$ \\
\hline Midline shift, 24 hours after OP (mm) & $3.6 \pm 3.3(3.0)$ & $8.8 \pm 6.8(6.7)$ & $10.0 \pm 8.1(8.0)$ & $7.5 \pm 6.3(5.0)$ \\
\hline ilCP (mmHg) & $33.5 \pm 15.9(30.0)$ & $35.7 \pm 14.5(36.0)$ & $31.0 \pm 15.5(27.0)$ & $32.3 \pm 17.8(30.0)$ \\
\hline vICP, mean value after OP (mmHg) & $18.4 \pm 11.4(14.8)$ & $22.3 \pm 16.3(15.6)$ & $17.3 \pm 11.0(14.0)$ & $17.3 \pm 11.0(14.0)$ \\
\hline Total DC area $\left(\mathrm{cm}^{2}\right)$ & $156.7 \pm 58.6(146.5)$ & $147.6 \pm 50.2(130.0)$ & $163.5 \pm 47.8(162.8)$ & $141.6 \pm 44.5(135.0)$ \\
\hline Total DC\% & $45.7 \pm 15.9(47.7)$ & $40.9 \pm 14.4(36.9)$ & $47.4 \pm 13.1(45.4)$ & $39.0 \pm 11.5(36.9)$ \\
\hline Offend side DC area $\left(\mathrm{cm}^{2}\right)$ & $107.2 \pm 30.9(100.0)$ & $125.1 \pm 19.3(125.0)$ & $117.7 \pm 26.2(110.5)$ & $125.9 \pm 27.4(135.0)$ \\
\hline Offend side DC\% & $61.9 \pm 13.7(62.8)$ & $69.1 \pm 10.5(72.8)$ & $68.1 \pm 13.1(69.4)$ & $69.1 \pm 12.5(69.8)$ \\
\hline ICP-difference & $15.1 \pm 11.5(13.7)$ & $13.4 \pm 11.2(15.0)$ & $13.8 \pm 13.5(14.3)$ & $12.1 \pm 13.6(12.6)$ \\
\hline Midline shift difference & $5.9 \pm 12.6(4.0)$ & $5.8 \pm 4.3(5.5)$ & $4.1 \pm 7.3(6.0)$ & $4.5 \pm 6.0(4.0)$ \\
\hline Unilateral : bilateral OP & $15: 25(37.5)$ & $16: 5(76.2)$ & $44: 52(45.9)$ & $137: 30(82.0)$ \\
\hline \multicolumn{5}{|l|}{ Clinical outcomes, GOS } \\
\hline 1, death & $13(32.5)$ & $10(47.6)$ & $32(33.3)$ & 66 (39.5) \\
\hline 2 & $11(27.5)$ & $6(28.6)$ & $20(20.8)$ & $31(18.6)$ \\
\hline 3 & $5(12.5)$ & $1(4.8)$ & $13(13.5)$ & $26(15.6)$ \\
\hline $4+5$, favor & $11(27.5)$ & $4(19.0)$ & 31 (32.3) & $44(26.3)$ \\
\hline 4 & $6(15.0)$ & $1(4.8)$ & $22(22.9)$ & $5(3.0)$ \\
\hline 5 & $5(12.5)$ & $3(14.3)$ & $9(9.4)$ & $39(23.4)$ \\
\hline
\end{tabular}

Values are expressed as mean \pm standard deviation (median), mean \pm standard deviation (\%), or number (\%) unless otherwise indicated. ICH : intracerebral hemorrhage, TBI : traumatic brain injury, iGCS : initial Glasgow coma scale, To OP time : accident to operation time, Midline shift : midline shift on brain computed tomography before the decompression craniectomy, ilCP : intracranial pressure after ventricular puncture, vICP : ventricular intracranial pressure after DC operation, Total DC area and DC\% : craniectomized bone sized and percentage of craniectomized bone sized over the total cranial vault size, Offend side DC area and DC\% : craniectomized bone sized and percentage of craniectomized bone sized over the main pathologic side cranial vault size, GOS : Glasgow outcome scale

eurysms, anterior circulation major cerebral infarction, $\mathrm{HICH}$, and TBI. Until now, few studies have compared clinical effects according to DC size and surgical methods. In authors' institute, surgical indications for decompressive operation and surgical techniques were constantly applied. However, the decision to perform either unilateral or bilateral DC, the amount of DC area was made by the operating surgeon. We analyzed clinical outcomes, ICP change, and other clinical factors according to surgical methods and DC area.

In our analysis, total DC area and DC\% were larger in the bilateral DC group than those in the unilateral group (both $p<0.001$, Table 1). However, offending side DC area and offending side DC\% failed to show statistically significant dif- ference in either DC group ( $p=0.753$ and $p=0.669$ ). DC surgery was effective for ICP change $(32.3 \pm 16.7 \mathrm{mmHg}$ vs. 19.2 \pm $13.4 \mathrm{mmHg}, p<0.001)$ and midline shift change $(12.5 \pm 7.6 \mathrm{~mm}$ vs. $7.8 \pm 6.9 \mathrm{~mm}, p<0.001)$. In the bilateral DC group, total DC area was larger $\left(125.1 \pm 27.8 \mathrm{~cm}^{2}\right.$ in the unilateral DC group vs. $198.2 \pm 43.0 \mathrm{~cm}^{2}$ in the bilateral group, $\left.p<0.001\right)$. And bilateral DC group shows more midline shift change $(p=0.015)$ than the unilateral group. This favorable midline shift change in bilateral DC group was not correlated with clinical outcomes, so midline shift improvement was not correlated with ICP decreasement ( $p=0.441)$ (Table 1$)$.

In some reports, larger DC is more effective than a standard DC in reducing the ICP, midline shift, and the incidence of 
secondary brain injury ${ }^{3,20,25-27,29,31,39)}$. Recent guideline regarding TBI treatment recommends that DC area should be at least $12 \times 15 \mathrm{~cm}\left(=180 \mathrm{~cm}^{2}\right)$ to improve the neurologic outcome $^{8)}$. In the present study, total DC area over $160 \mathrm{~cm}^{2}$ showed significantly better neurologic outcome $(p=0.020)$ and midline shift improvement $(p=0.014)$ than total DC area under $160 \mathrm{~cm}^{2}$. This amount of DC\% may be $46 \%$ in DC\% scale and this also correlated well with clinical outcomes $(p=0.037)$.

To avoid secondary injury and proper tissue perfusion for metabolic homeostasis, various neurocritical care processes are recommended $\mathrm{d}^{1-6,9,14,23,33,36)}$. In this study, authors followed guidelines' recommendation to maintain postoperative ICP trend (under $15 \mathrm{mmHg}$ ) and CPP (over $70 \mathrm{mmHg})^{5-8,31,36)}$.

However, for MI patients, immediate surgical intervention is not recommended for all cases (Table 2). However, in some patients with MIs, brain swelling is not severe enough to necessitate DC. Good neurological outcomes without DC could be explained by the recruitment of collateral circulation and a diffusional effect without recanalization of the occluded artery, even when there is major vessel occlusion. Therefore, the authors performed DC for patients with major vessel occlusion following changes of the neurological status, not by a time schedule. The mean time between the onset of infarction symptoms and DC was 44 hours (median, 32 hours). Several studies have evaluated DC surgery in MI patients and concluded that early surgery is essential to good clinical outcome $e^{13,15,17,20,21,32,38)}$. However, some studies have reported that maximal brain swelling after MI can develop at 2-3 days after an ischemic insult ${ }^{31,34)}$.

Some reports commented that, although a large proportion of survivors also experience unfavorable functional outcomes, DC surgery might be mainly effective in reducing the elevated $\mathrm{ICP}^{4,10,11,19,25,32,33)}$.

From this study, bilateral DC shows larger total DC size but clinical outcome was not significant favorable compare the unilateral DC. Authors thought that total DC size is important for improve the DC surgical effect. But we also consider the pathologic site that cause brain swelling and ICP increase.

This study has several limitations that might affect interpretation of the result. First, this study is single center and retrospective study without randomization. Second, this cohort is inhomogeneous. DC has been done for multiple pathologies which could give confusion in interpreting result. Unlike this study, two well-known randomized controlled trials showed that early DC in severe diffuse brain injury and refractory intracranial hypertension was associated with a worse functional outcome $e^{10,19)}$. Because of heterogeneity of pathology, this study showed that DC was associated with a favorable functional outcome. So, further study should be needed after separating out the different pathologies.

\section{CONCLUSION}

DC can effectively lower increased ICP and improve neurological outcomes in patients with uncontrollable increased ICP. In this study, there was no difference in ICP change or neurologic outcomes between unilateral and bilateral DC. However, total DC area over $160 \mathrm{~cm}^{2}$ may be beneficial for improving neurologic outcome, midline shift, and ICP control. This study suggests that not only total DC area, but also DC location near the pathology lesion site should be considered to improve the surgical effects of DC. And larger unilateral DC surgery is more convenient for operation procedure and favorable for clinical outcomes of the patient.

\section{CONFLICTS OF INTEREST}

No potential conflict of interest relevant to this article was reported.

\section{INFORMED CONSENT}

This type of study does not require informed consent.

\section{AUTHOR CONTRIBUTIONS}

\author{
Conceptualization : KWJ, DSY \\ Data curation : WIJ, HKP \\ Formal analysis : WIJ \\ Methodology : KWJ, DSY \\ Project administration : KWJ, DSY, HKP, WIJ \\ Visualization : HKP, WIJ \\ Writing - original draft : KWJ \\ Writing - review \& editing : DSY
}




\section{ORCID}

$\begin{array}{ll}\text { KwangWook Jo } & \text { https://orcid.org/0000-0001-7993-3409 } \\ \text { Won Il Joo } & \text { https://orcid.org/0000-0002-4120-1699 } \\ \text { Do Sung Yoo } & \text { https://orcid.org/0000-0003-2569-6502 } \\ \text { Hae-Kwan Park } & \text { https://orcid.org/0000-0001-7132-7009 }\end{array}$

\section{References}

1. Andrews PJ, Sinclair HL, Rodriguez A, Harris BA, Battison CG, Rhodes $J K$, et al. : Hypothermia for intracranial hypertension after traumatic brain injury. N Engl J Med 373 : 2403-2412, 2015

2. Bor-Seng-Shu E, Figueiredo EG, Amorim RL, Teixeira MJ, Valbuza JS, de Oliveira MM, et al. : Decompressive craniectomy: a meta-analysis of influences on intracranial pressure and cerebral perfusion pressure in the treatment of traumatic brain injury. J Neurosurg 117 : 589-596, 2012

3. Bor-Seng-Shu E, Figueiredo EG, Fonoff ET, Fujimoto Y, Panerai RB, Teixeira MJ : Decompressive craniectomy and head injury: brain morphometry, ICP, cerebral hemodynamics, cerebral microvascular reactivity, and neurochemistry. Neurosurg Rev 36 : 361-370, 2013

4. Bösel J, Zweckberger K, Hacke W : Haemorrhage and hemicraniectomy: refining surgery for stroke. Curr Opin Neurol 28 : 16-22, 2015

5. Brain Trauma Foundation; American Association of Neurological Surgeons; Congress of Neurological Surgeons : Guidelines for the management of severe traumatic brain injury. J Neurotrauma 24 Suppl 1 : S1-S106, 2007

6. Brain Trauma Foundation; American Association of Neurological Surgeons; Joint Section on Neurotrauma and Critical Care : Guidelines for the management of severe head injury. J Neurotrauma $13: 641-734$, 1996

7. Bratton SL, Chestnut RM, Ghajar J, McConnell Hammond FF, Harris OA, Hartl R, et al. : Guidelines for the management of severe traumatic brain injury. VIII. Intracranial pressure thresholds. J Neurotrauma 24 Suppl $1:$ S55-S58, 2007

8. Carney N, Totten AM, O'Reilly C, Ullman JS, Hawryluk GW, Bell MJ, et al. : Guidelines for the management of severe traumatic brain injury, fourth edition. Neurosurgery $80: 6-15,2017$

9. Clifton $G L$, Allen $S$, Barrodale $P$, Plenger $P$, Berry J, Koch $S$, et al. : A phase II study of moderate hypothermia in severe brain injury. J Neurotrauma 10 : 263-271; discussion 273, 1993

10. Cooper DJ, Rosenfeld JV, Murray L, Arabi YM, Davies AR, D'Urso P, et al. : Decompressive craniectomy in diffuse traumatic brain injury. $\mathbf{N}$ Engl J Med 364 : 1493-1502, 2011

11. El Ahmadieh TY, Adel JG, El Tecle NE, Daou MR, Aoun SG, Nanney AD 3rd, et al. : Surgical treatment of elevated intracranial pressure: decompressive craniectomy and intracranial pressure monitoring. Neurosurg Clin N Am 24 : 375-391, 2013

12. Ferro JM, Crassard I, Coutinho JM, Canhão P, Barinagarrementeria $F$, Cucchiara $B$, et al. : Decompressive surgery in cerebrovenous thrombo- sis: a multicenter registry and a systematic review of individual patient data. Stroke 42 : 2825-2831, 2011

13. Frank JI, Schumm LP, Wroblewski K, Chyatte D, Rosengart AJ, Kordeck

$C$, et al. : Hemicraniectomy and durotomy upon deterioration from infarction-related swelling trial: randomized pilot clinical trial. Stroke 45 : 781-787, 2014

14. Gerber LM, Chiu YL, Carney N, Härtl R, Ghajar I : Marked reduction in mortality in patients with severe traumatic brain injury. J Neurosurg 119 : 1583-1590, 2013

15. Güresir E, Schuss P, Seifert V, Vatter H : Decompressive craniectomy in children: single-center series and systematic review. Neurosurgery 70 : 881-888; discussion 888-889, 2012

16. Ho MY, Tseng WL, Xiao F : Estimation of the craniectomy surface area by using postoperative images. Int J Biomed Imaging 2018 : 5237693, 2018

17. Hofmeijer J, Kappelle LJ, Algra A, Amelink GJ, van Gijn J, van der Worp $H B$, et al. : Surgical decompression for space-occupying cerebral infarction (the hemicraniectomy after middle cerebral artery infarction with life-threatening edema trial [HAMLET]): a multicentre, open, randomised trial. Lancet Neurol 8 : 326-333, 2009

18. Honeybul $\mathrm{S}$, Ho KM : The current role of decompressive craniectomy in the management of neurological emergencies. Brain Inj 27 : 979-991, 2013

19. Hutchinson PJ, Kolias AG, Timofeev IS, Corteen EA, Czosnyka M, Timothy J, et al. : Trial of decompressive craniectomy for traumatic intracranial hypertension. N Engl J Med 375 : 1119-1130, 2016

20. Jiang JY, Xu W, Li WP, Xu WH, Zhang J, Bao YH, et al. : Efficacy of standard trauma craniectomy for refractory intracranial hypertension with severe traumatic brain injury: a multicenter, prospective, randomized controlled study. J Neurotrauma 22 : 623-628, 2005

21. Jüttler $E$, Schwab S, Schmiedek P, Unterberg A, Hennerici M, Woitzik J, et al. : Decompressive surgery for the treatment of malignant infarction of the middle cerebral artery (DESTINY): a randomized, controlled trial. Stroke 38 : 2518-2525, 2007

22. Kakar V, Nagaria J, John Kirkpatrick P : The current status of decompressive craniectomy. Br J Neurosurg 23 : 147-157, 2009

23. Kenning TJ, Gooch MR, Gandhi RH, Shaikh MP, Boulos AS, German JW : Cranial decompression for the treatment of malignant intracranial hypertension after ischemic cerebral infarction: decompressive craniectomy and hinge craniotomy. J Neurosurg 116 : 1289-1298, 2012

24. Kim KT, Park JK, Kang SG, Cho KS, Yoo DS, Jang DK, et al. : Comparison of the effect of decompressive craniectomy on different neurosurgical diseases. Acta Neurochir (Wien) $151: 21-30,2009$

25. Lang SS, Kofke WA, Stiefel MF : Monitoring and intraoperative management of elevated intracranial pressure and decompressive craniectomy. Anesthesiol Clin 30 : 289-310, 2012

26. Lazaridis C, Czosnyka M : Cerebral blood flow, brain tissue oxygen, and metabolic effects of decompressive craniectomy. Neurocrit Care 16 : 478-484, 2012

27. Lazaridis C, DeSantis SM, Vandergrift AW, Krishna V : Cerebral blood flow velocity changes and the value of the pulsatility index post decom- 
pressive craniectomy. J Clin Neurosci 19 : 1052-1054, 2012

28. Marshall LF, Smith RW, Shapiro HM : The outcome with aggressive treatment in severe head injuries. Part I: the significance of intracranial pressure monitoring. J Neurosurg $50:$ 20-25, 1979

29. Missori P, Morselli C, Domenicucci M, Paolini S, Peschillo S, Scapeccia $M$, et al. : Measurement of bone flap surface area and midline shift to predict overall survival after decompressive craniectomy. World Neurosurg $96: 11-14,2016$

30. Morgalla MH, Will BE, Roser F, Tatagiba M : Do long-term results justify decompressive craniectomy after severe traumatic brain injury? J Neurosurg 109 : 685-690, 2008

31. Neugebauer H, Fiss I, Pinczolits A, Hecht N, Witsch J, Dengler NF, et al. : Large size hemicraniectomy reduces early herniation in malignant middle cerebral artery infarction. Cerebrovasc Dis 41 : 283-290, 2016

32. Rahme R, Zuccarello M, Kleindorfer $D$, Adeoye OM, Ringer AJ : Decompressive hemicraniectomy for malignant middle cerebral artery territory infarction: is life worth living? J Neurosurg 117 : 749-754, 2012

33. Rosenfeld JV, Maas Al, Bragge P, Morganti-Kossmann MC, Manley GT, Gruen RL : Early management of severe traumatic brain injury. Lancet 380 : 1088-1098, 2012

34. Saul TG, Ducker TB : Effect of intracranial pressure monitoring and aggressive treatment on mortality in severe head injury. J Neurosurg 56 : 498-503, 1982

35. Schirmer CM, Hoit DA, Malek AM : Decompressive hemicraniectomy for the treatment of intractable intracranial hypertension after aneurysmal subarachnoid hemorrhage. Stroke 38 : 987-992, 2007

36. The Brain Trauma Foundation; The American Association of Neurological Surgeons; The Joint Section on Neurotrauma and Critical Care : Intracranial pressure treatment threshold. J Neurotrauma $17:$ 493-495, 2000

37. Ucar $T$, Akyuz $M$, Kazan $S$, Tuncer $R$ : Role of decompressive surgery in the management of severe head injuries: prognostic factors and patient selection. J Neurotrauma 22 : 1311-1318, 2005

38. Vahedi K, Vicaut E, Mateo J, Kurtz A, Orabi M, Guichard JP, et al. : Sequential-design, multicenter, randomized, controlled trial of early decompressive craniectomy in malignant middle cerebral artery infarction (DECIMAL trial). Stroke 38 : 2506-2517, 2007

39. Won YD, Yoo DS, Kim KT, Kang SG, Lee SB, Kim DS, et al. : Cranioplasty effect on the cerebral hemodynamics and cardiac function. Acta Neurochir Suppl $102: 15-20,2008$

40. Xiao $B$, Wu FF, Zhang $H, M a Y B$ : A randomized study of urgent computed tomography-based hematoma puncture and aspiration in the emergency department and subsequent evacuation using craniectomy versus craniectomy only. J Neurosurg 117 : 566-573, 2012

41. Yoo DS, Kim DS, Cho KS, Huh PW, Park CK, Kang JK : Ventricular pressure monitoring during bilateral decompression with dural expansion. J Neurosurg 91 : 953-959, 1999

42. Zhao J, Su YY, Zhang Y, Zhang YZ, Zhao R, Wang L, et al. : Decompressive hemicraniectomy in malignant middle cerebral artery infarct: a randomized controlled trial enrolling patients up to 80 years old. Neurocrit Care 17 : 161-171, 2012 